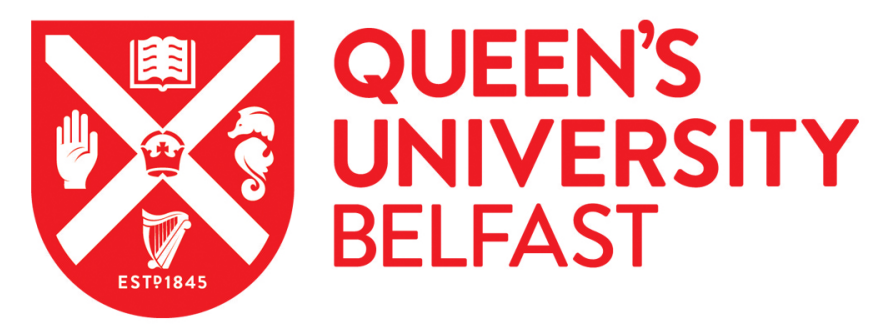

\title{
Creep and interfacial behavior of carbon fiber reinforced epoxy filament wound laminates
}

Almeida Jr, H., Ornaghi Jr, H. L., Lorandi, N. P., Bregolin, B. P., \& Amico, S. C. (2018). Creep and interfacial behavior of carbon fiber reinforced epoxy filament wound laminates. Polymer Composites, 34(S4), E2199E2206. https://doi.org/10.1002/pc.24537

\section{Published in:}

Polymer Composites

\section{Document Version:}

Peer reviewed version

Queen's University Belfast - Research Portal:

Link to publication record in Queen's University Belfast Research Portal

\section{Publisher rights}

Copyright 2017, Wiley.

This work is made available online in accordance with the publisher's policies. Please refer to any applicable terms of use of the publisher.

\section{General rights}

Copyright for the publications made accessible via the Queen's University Belfast Research Portal is retained by the author(s) and / or other copyright owners and it is a condition of accessing these publications that users recognise and abide by the legal requirements associated with these rights.

Take down policy

The Research Portal is Queen's institutional repository that provides access to Queen's research output. Every effort has been made to ensure that content in the Research Portal does not infringe any person's rights, or applicable UK laws. If you discover content in the Research Portal that you believe breaches copyright or violates any law, please contact openaccess@qub.ac.uk. 


\title{
CREEP AND INTERFACIAL BEHAVIOR OF CARBON FIBER REINFORCED EPOXY FILAMENT WOUND LAMINATES
}

\author{
José Humberto S. Almeida Jr. ${ }^{a^{*}}$, Heitor L. Ornaghi Jr. ${ }^{c}$, Natália P. Lorandic, Bernardo P. \\ Bregolin ${ }^{c}$, Sandro C. Amico ${ }^{a}$
}

${ }^{a}$ PPGE3M, Federal University of Rio Grande do Sul, Av. Bento Gonçalves, 9500, 91501-970, Porto Alegre, RS, Brazil.

${ }^{b}$ Department of Composite Materials, Leibniz-Institut für Polymerforschung Dresden e.V., Hohestraße 6, 01067 Dresden, Germany

'PGMAT, Caxias do Sul University, Rua Francisco Getúlio Vargas, 1130, 95070-560, Caxias do Sul, RS, Brazil.

\begin{abstract}
This paper focuses on the investigation of the interfacial and creep characteristics of carbon fiberreinforced epoxy laminates at different fiber orientations. Flat unidirectional 12-layer laminates were manufactured by dry-filament winding and cured under hot compression. The following winding sequences were studied: $[0]_{12},[30]_{12},[45]_{12},[60]_{12}$ and $[90]_{12}$. Short-beam testing aided by microscopy and dynamic mechanical analysis were used to assess interfacial characteristics and creep behavior of the laminates. Short beam strength and creep behavior were strongly influenced by fiber orientation. Short beam strength decreased $270 \%$, and only the laminates wound at $0^{\circ}$ presented delamination purely at the mid-plane. Fiber/matrix stress transfer is more
\end{abstract}

*Corresponding author: E-mail: jhsajunior@globomail.com; humberto@ipfdd.de

Phone: +49 3514658 1423; Fax: +49 3514658362 
efficient for laminates wound at $0^{\circ}$, providing better creep behavior. Dynamic mechanical analysis results indicated the storage modulus to be dependent on the ply angle. Findley's and Burger's fitting were used to analyze creep data from the DMA and correlate structure and property of the composites. The creep strain increases from longitudinal to transversal fiber orientation and by increasing the temperature. At higher temperatures, samples longitudinally oriented exhibited an elastic behavior, with good agreement with the Findley's model.

Keywords: Creep; interface; interlaminar; analytical modeling; viscoelasticity; filament winding.

\section{Introduction}

Carbon fiber reinforced polymer (CFRP) composites are well known to possess high stiffness- and strength-to-weight ratio, as well as lack of corrosion. Among others, marine, aerospace and aeronautic areas are continuously replacing metallic structural counterparts by composite ones, in order to increase payload [1,2]. Nevertheless, the use of advanced composites in structural counterparts is still limited. One of the reasons is that their mechanical properties, including interfacial and interlaminar properties are significantly dependent on time, temperature and fiber orientation. For instance, laminas are not prone to creep when loaded in the fiber direction, but this does not occur when there is a mismatch between them, which can lead to excessive strain and premature failure [3].

The mechanical performance of a composite with fibers embedded into a polymeric matrix strongly depends on its fiber/matrix interface and on suitable interfacial fiber/matrix bonding. There are some micromechanical methods to evaluate interfacial strength, such as pushout [4] and pull-out [5] tests. However, apart from their complexity, they are mostly unable to evaluate the effect of fiber orientation on the interfacial strength since a single fiber is embedded in a matrix. In this way, a more macroscopic method to assess fiber/matrix interface is more 
appropriate. The short beam test is suitable to correlate fiber orientation and interfacial stress transfer capability, easily enabling direct evaluation of interlaminar strength or indirect evaluation of interfacial strength [6,7].

In addition, study of the influence of fiber orientation on long-term characteristics of these laminates is essential for safe design. Creep refers to a time-dependent deformation under a constant load at a specified temperature. Creep is considered a crucial material property at a longterm point of view [8]. For composites, creep resistance is directly associated with viscoelastic strain and fiber/matrix interfacial behavior. Since temperature, stress and time are crucial parameters to describe viscoelastic behavior, especially when the fiber/matrix coupling needs to be assessed, several models have been proposed to predict long-term creep behavior of composites $[9,10,11]$.

Among the proposed models, Findley et al. [12] used an empirical power equation to describe creep behavior of several polymers with good accuracy over a wide time-scale. According to Yang et al. [13], this power law is suitable for materials that do not exhibit a pronounced second creep stage, especially under low stress, which is the case of the current study. However, it is difficult to interpret the results due to numerous variables involved in this model, including degree of crosslinking of the matrix, which may vary between bulk and close to the fiber interface, physical aging, temperature and moisture effects, matrix shrinkage under isothermal curing, and thermal expansion of both resin and fiber [14]. Another important model is the Burger's creep model [15], also known as the four-parameter model, which includes the essential Maxwell and Kelvin-Voigt elements and can satisfactorily model the practical behavior of viscoelastic materials [13].

Goertzen and Kessler [16] evaluated creep behavior of carbon/epoxy composites under tensile and flexural loadings and concluded by extrapolating creep results that the material would 
not fail below $65 \%$ of the tensile strength for $1600 \mathrm{~h}$. Melo and Medeiros [17] determined creeprupture failure of epoxy coupons based on tensile, compressive and dynamic-mechanical tests at different temperatures, and produced master curves and failure envelopes based on the Tsai-Wu criterion. In addition, Ha et al. [18] concluded that, in order to obtain standard master curves to describe creep-rupture of polymer and/or composites, suitable properties, such as constituent strengths, should be directly measured.

In this context, the scope of this work is to apply both Findley's and Burger's models to predict creep behavior of carbon fiber reinforced epoxy filament wound flat laminates and validate the analytical results with experimental ones. In addition, short beam strength is used to indirectly assess the interfacial characteristics of the laminates.

\section{Experimental}

\subsection{Materials \& manufacturing}

Carbon fiber reinforced epoxy prepreg tow (usually known as towpreg) from TCR Composites, which is composed of Toray T700-12K-50C carbon fibers and UF3369 epoxy as resin system, was used. The flat laminates were produced using a rectangular stainless steel mandrel $\left(327 \times 228 \times 12 \mathrm{~mm}^{3}\right)$ in a filament winding system from MFTech coupled with a KUKA robot KR 140 L100. The towpregs were wound onto the mandrel and then a shrink tape was used to help consolidating the laminate throughout the curing process that followed.

The laminates were cured by hot compression under 6 ton for $4 \mathrm{~h}$ at $130{ }^{\circ} \mathrm{C}$. The final fiber volume fraction was $\approx 72 \%$ (measured by acid digestion following ASTM D3171) and overall mean thickness of the 12-layer laminate was $4.2 \mathrm{~mm}$. Unidirectional laminates were produced and the specimens were cut using a CNC machine at different off-axis angles, producing the following laminates: $[0]_{12},[30]_{12},[45]_{12},[60]_{12}$ and $[90]_{12}$. 


\subsection{Characterization}

The dynamic mechanical and creep behavior were assessed using a dynamic mechanical analyzer DMA Q-800 equipment from TA instruments. Three samples having dimensions of $50 \times$ $10 \times 4 \mathrm{~mm}^{3}$ were used for DMA tests under three-point mode with a span-to-thickness ratio of 12:1. General dynamic mechanical analysis was performed first aiming to detect mobility regions. Two runs were carried out under the following conditions: $25-150{ }^{\circ} \mathrm{C}$ temperature range, heating rate of $3{ }^{\circ} \mathrm{C} / \mathrm{min}$ (in the first run $10{ }^{\circ} \mathrm{C} / \mathrm{min}$ ), constant frequency of $1 \mathrm{~Hz}$, pre-load of $0.1 \mathrm{~N}$, amplitude of $15 \mu \mathrm{m}$, and force track of $125 \%$. The second run was performed seeking to avoid interface concerns $[19,20]$.

Creep tests were carried out using the same three-point bending setup, sample dimensions and DMA equipment. A static stress value of $2 \mathrm{MPa}$ was applied at the center point along the length of the sample for $10 \mathrm{~min}$ after conditioning at $30{ }^{\circ} \mathrm{C}$, and creep strain was measured as a function of time $(30 \mathrm{~min})$ at constant temperature $\left(30^{\circ} \mathrm{C}\right)[9,12]$.

Findley's and Burger's models were applied to predict creep behavior of the laminates. Findley's power law is given by:

$$
\varepsilon(t)=\varepsilon_{0}+A t^{n}
$$

where $\varepsilon(t)$ is the creep strain at time $t, \varepsilon_{0}$ is the instantaneous elastic strain or timeindependent, $A$ is the amplitude of transient creep (time-dependent) and $n$ is a constant independent of the stress and generally less than one [12,21].

Burger's model (Eq. 2) is shown in Eq. (2):

$$
\varepsilon(t)=\frac{\sigma_{0}}{E_{M}}+\frac{\sigma_{0}}{e_{K}\left(1-e^{\left.-E_{K} t / \eta_{K}\right)}\right.}+\frac{\sigma_{0}}{\eta_{M}}
$$


where $\sigma_{0}$ is the stress, $E_{M}$ is the elastic modulus of the Maxwell model (spring), $E_{K}$ is the elastic modulus of the Kelvin model, $\eta_{M}$ and $\eta_{K}$ are the viscosities of Maxwell and Kelvin dashpots, respectively. The first term is a constant related to the deformation of the Maxwell model, the second represents the early creep stage, and the third the creep trend at a sufficiently long time [9].

The interfacial behavior was investigated using short-beam test, following ASTM D2344-13 using a span-to-thickness ratio of 4:1. Length and width of the specimens are $24 \mathrm{~mm}(6 \times t)$ and $8 \mathrm{~mm}(2 \times t)$, respectively. The short beam strength (SBS) was calculated by Equation (3). Ten specimens were tested in each case and fractographic studies of failed specimens were carried out using optical microscopy, in a Carl Zeiss Axioscope, and scanning electron microscopy (SEM), in a Phenom ProX equipment.

$$
S B S=0.75 \frac{P}{w t}
$$

where $P, w$ and $t$ are the ultimate load, width and thickness of the specimen, respectively.

\section{Results and discussion}

\subsection{Interfacial characteristics}

The interfacial behavior is herein indirectly evaluated through short-beam testing, formerly known as interlaminar shear strength (ILSS). Figure 1 depicts the typical short beam stress vs. displacement for the on- and off-axis laminates studied. The strong influence of fiber orientation on interlaminar behavior of the specimens is clear. The [0] 12 specimens presents the most non-linear behavior, where several load drops can be seen after the maximum load is achieved, which is caused by multiple horizontal cracks on the specimens. A large delamination 
at the mid-plane of the specimen is reported, which is observed at the final load drop [22] and clearly corroborates the SEM images of the $[0]_{12}$ fractured specimen (Figure $2 \mathrm{a}-\mathrm{b}$ ).

The stress supported by the specimens wound at higher angles is lower than the $[0]_{12}$ sample, as would be expected for unidirectional composites subjected to 3-point bending. The $[30]_{12}$ and $[45]_{12}$ coupons present less non-linearity in their curves, with less evidences of shear failure. Furthermore, specimens oriented at [60 $]_{12}$ and $[90]_{12}$ support almost the same stress, with similar stress $v s$. displacement profile. The abrupt drop noticed in some of the specimens is an indication that bending and compressive loads are more important in this case, and the lack of fibers along the longitudinal direction promotes sudden failure. Thus short-beam strength, similarly to other composites properties, increases when the reinforcement is oriented along the loading direction [23].

\section{$<<$ Insert Figure1 $>>$}

Daniels et al. [24] listed all possible failure modes involved in short-beam testing. The $[0]_{12}$ coupon had discrete shear failure characterized by a large single horizontal crack, and the final load drop represents delamination. The [30] 12 and [45] $]_{12}$ samples had homogeneous shear failure, which is characterized by a clear final load drop and small cracks distributed along the specimen. Failure in the $[60]_{12}$ and $[90]_{12}$ coupons were dominated by tensile forces, with a vertical opening of the major crack centrally located at the bottom surface and a brittle failure.

Figure 2 presents the post-mortem analysis of the SBS fractured $[0]_{12}(a-b)$ and $[90]_{12}$ specimens (c-d). Failure in $[0]_{12}$ specimens occurred as expected for this type of loading, since a large delamination at the mid-plane of the specimen thickness and multiple minor horizontal cracks were found, characterizing interlaminar shear failure. That is, a simple shear state was generated on the test since parallel regions slide in opposite directions, generating horizontal cracks and delamination. On the other hand, [90 $]_{12}$ specimens have a matrix-dominated failure 
with no evidence of shear since a vertical crack initiated at the specimen upper surface between the supporting cylinders, characterizing failure by flexure and primarily transverse tensile, corroborated by the brittle behavior of the epoxy resin.

\section{$<<$ Insert Figure 2〉>}

The other failed short-beam specimens are presented in Figure 3. Optical microscopies corroborate delamination and horizontal minor cracks at the thickness mid-plane for $[0]_{12}$ specimens, confirming interlaminar shear failure. On the off-axis specimens, multiple cracks can be found in the fiber direction. A combination of shear and tensile loads acting on the specimen are found, confirmed by a slight influence of bending during the test.

\section{$<<$ Insert Figure 3>>}

\subsection{Dynamic mechanical behavior}

Dynamic mechanical analysis of the composites was carried out aiming to observe initial regions where molecular mobility takes place. Figure 4 presents storage and loss moduli, and tan delta of the composites. Large differences are noticed among the laminates in the glassy region from $0^{\circ}$ to $90^{\circ}$ loading direction. This is due to distinct stress transfer efficiency, where for composites transversally oriented, adhesion forces play a major role. For the $[0]_{12}$ specimen, the fibers carry nearly all applied load, thus greater modulus is expected.

\section{$<<$ Insert Figure 4 >>}

Loss modulus refers to dissipated energy in the senoidal deformation cycle and it was used here to select the temperatures for the creep tests, i.e. 30 and $60{ }^{\circ} \mathrm{C}$, being both in the glassy region. It is noted that peak height varies in accordance to the storage modulus, and the higher the drop in storage modulus above the glassy region, the higher the loss modulus peak. This results in similar tan delta curve shapes [25]. 
According to Akay [26], E” gives a better indication of the molecular mobility in composites materials compared to tan delta. However, Qin and McKenna [27] showed that the activation energy is more useful for classifying the temperature dependency of the dynamic properties than the glass transition temperature $\left(T_{g}\right)$. In the current study, $T_{g}$ values were collected from the loss and tan delta curves aiming to further investigate this (Table 1).

Tan delta curves indicate that $T_{g}$ is similar for all orientations, considering the errors involved $\left( \pm 5{ }^{\circ} \mathrm{C}\right)$ and that fiber and matrix systems are the same in all samples [28]. $\mathrm{T}_{\mathrm{g}}$ values remain almost the same because thermal conductivity distribution is more uniform, and (since the resin is the same) sensitivity to variations experienced by the resin is not so pronounced. It is important to mention that $T_{g}$ is not the best way to evaluate molecular mobility and does not represent the reinforcement effect, as mentioned earlier. The tan delta peak height also indicates energy dissipation in the composite and higher peak height suggests poorer interface, which can be a consequence of the variable stress transferring efficiency.

\section{$<<$ Insert Table $1>>$}

According to Table 1, no significant differences among the results are seen. In Akay's study [26], a more pronounced variation $(\Delta T)$ was achieved, and the loss modulus peak was a more consistent indicator of the mechanical behavior of the composite. The divergence could be justified by a combination of factors such as the non-uniform compliance in the matrix due to fiber-matrix interactions (which considerably changes with fiber orientation). In the current study, deformation from thermal effects is not so pronounced due to the processing method used, which gives a more uniform structural composite, with very different storage modulus range. For the sample longitudinally oriented, this difference was lower in comparison to the other specimens due to a more efficient thermal conductivity resulting in a more uniform temperature 
distribution, which narrows the difference between moduli. Higher difference is achieved for transversely oriented coupons (which show similar $\Delta T$ due to similar thermal conductivity).

\subsection{Creep behavior}

Creep curves for all laminates at a stress level of $2 \mathrm{MPa}$ at $30{ }^{\circ} \mathrm{C}$ and $60{ }^{\circ} \mathrm{C}$ are shown in Figures 5 (a)-(b), along with the fitting obtained using both Findley's and Burger's models. It can be clearly noted that creep behavior changes with the orientation angle, especially instantaneous deformation (initial deformation). All curves follow the classical creep curve trend, as reported by Findley [12]. From these curves, Findley's and Burger's model parameters were calculated and are presented in Table 2 and Table 3, respectively.

Findley's parameter $A$ was found to increase from $[0]_{12}$ to $[90]_{12}$, as expected. This means that instantaneous deformation is higher due to poorer stress transfer for transversely oriented specimens. Furthermore, since fiber/matrix interactions are of the frictional type, transverse load is more prone to creep since it relies purely on tensile decoupling of the fiber/matrix interface. The $n$ parameter was found to decrease with the angle but this is not necessarily related to any particular characteristic of the material $[9,10,21]$.

By increasing the temperature, a similar trend is observed in relation to fiber orientation. However, greater deformation is noted due to higher molecular mobility promoted by thermal effects. Overall, the systems are in a more relaxed state, so even small perturbations (which are dependent on volume, for example) are sufficient to promote conformational relaxation, which affects the change in volume. The structural change in response of temperature variation is then more pronounced. However, as the ply angle increases, the Burger's model fitting becomes unsuitable, which can be associated with higher mobility degree due to thermal effects [9].

\section{$<$ Insert Figure 5>>}




\section{$<<$ Insert Table 2 >>}

All Burger's parameters (Table 3) were discussed considering the present system, which differs from a semi crystalline matrix, for instance. In this study, $E_{M}$ can be associated with the instantaneous modulus and represents the composite stiffness regarding stress application. In our study, similar results were found. It is expected that $0^{\circ}$ angle yields higher values in comparison to $90^{\circ}$, considering the previous storage modulus results. Since a low stress level was applied in the creep tests, this behavior remains nearly unaltered.

The $\eta_{M}$ parameter corresponds to the irreversible deformation in the amorphous regions, or the irrecoverable creep. A decreasing trend is observed for this parameter, which can be associated with the polymer chains restrained due to a more efficient stress transfer. The $\eta_{K}$ parameter is related to the viscosity of the amorphous regions and a decreasing trend is observed, associated to the increase in mobility of molecular chains of the matrix. In the studied composites, this decrease is perhaps justified by a more equally distributed stress between matrix and fibers, as the orientation changes from $0^{\circ}$ to $90^{\circ}$. Thus, greater mobility is obtained for the composites in which the matrix carries relatively more stress and short-term viscosity of the amorphous polymer chains increases.

Finally, $E_{K}$ is associated to the short-term stiffness of the amorphous polymer chains. In this study, higher values were obtained from $0^{\circ}$ to $90^{\circ}$ oriented specimens. This behavior can be associated with lower deformation under low stress, which corroborates the reported $\eta_{K}$ parameter.

\section{$\langle<$ Insert Table 3>>}

\section{Conclusions}


The scope of the present study was to evaluate the interfacial behavior of carbon fiber reinforced epoxy laminates manufactured by filament winding. Interfacial characteristics with respect to fiber orientation, $[0]_{12},[30]_{12},[45]_{12},[60]_{12}$ and $[90]_{12}$, were assessed through short beam tests and creep analyses.

A significant drop in short beam strength was observed for a change in fiber orientation of $30^{\circ}$, justified by the high anisotropy of the unidirectional composites. When the fiber is oriented at an angle higher than $30^{\circ}$, the mechanical response is more dependent on the matrix system and the interface, yielding lower short beam strength. Post-mortem analyses confirm that specimens oriented at $0^{\circ}$ fail essentially by interlaminar shear, since delamination at the specimen mid-plane was found. For the other specimens, the main failure occurred at the bottom surface, indicating bending effects.

The viscoelastic behavior is also dependent on fiber orientation, as well as the creep performance. Storage and loss moduli showed great dependency with fiber orientation, and the overall curves were used to determine parameters of the creep analytical models. Both Burger's and Findley's models were suitable to predict creep behavior of the unidirectional specimens herein analyzed, showing good fitting of the experimental data. A larger difference in fitting is observed at higher temperature. As the angle ply increases, Burger's seems not to adjust to the experimental data as well as Findley's.

Findley's power law is simpler and can satisfactory express long-term creep properties, whereas Burger's provides a more constitutive model, and allows a more detailed structure-toproperty relationship analysis. A larger difference was noticed at higher temperatures being only satisfactorily adjusted using a three-parameter model (Findley's).

\section{Acknowledgments}


The authors would like to thank AEB (Brazilian Space Agency), CAPES and CNPq for the financial support.

\section{References}

1. J.H.S. Almeida Júnior, M.L. Ribeiro, V. Tita, S.C. Amico, Mater. Des., 96, 431 (2016).

2. J.H.S. Almeida Júnior, M.L. Ribeiro, V. Tita, S.C. Amico, Compos. Struct., 160, 204 (2017).

3. K.S. Fancey and A. Fanzal, Polym.Compos., 37(7), 2092 (2015).

4. X.F. Zhou, H.D. Wagner, S.R. Nutt, Compos. Part.A-Appl. S., 32(11), 1543 (2001).

5. S. Zhandarov and E. Mäder, Compos. Sci. Technol., 65(1), 149 (2005).

6. J.H.S. Almeida Jr., C.C. Angrizani, E.C. Botelho, S.C. Amico, Mater. Des., 65, 789 (2015).

7. J.H.S. Almeida Jr. S.D.B. Souza, E.C. Botelho, S.C. Amico. J. Mater. Sci., 51(9), 4697 (2016).

8. M.I. Faraz, N.A.M. Besseling, A.V. Korobko, S.J. Picken, Polym. Compos., 36(2), 322 (2015).

9. J. Militký and A. Jabbar, Compos. B Eng., 80, 361 (2015).

10. R.M. Guedes, Mech. Time-Depend. Mat., 8(2), 169 (2004).

11. S. Deng, M. Hou, L. Ye, Polym. Test., 26(6), 803 (2007).

12. W.N. Findley, J.S. Lai, K. Onaran, North-Holland Publishing Company, 1976.

13. J-L. Yang, Z. Zhang, A. Schlarb, K. Friedrich, Polymer, 47(8), 2791 (2006).

14. A.R. Maligno, N.A. Warrior, A.C. Long, Express. Polym. Lett.,2(9), 665 (2008).

15. M.I. Faraz, N.A.M. Besseling, A.V. Korobko, S.J. Picken, Polym. Compos., 36(2), 322 (2015).

16. W.K. Goertzen and M.R. Kessler. Mater.Sci. Eng. A., 421(1-2), 217 (2006).

17. J.D.D. Melo and A.M. Medeiros, Mech. Time-Depend. Mat., 18(1), 113 (2013).

18. S.K. Ha, K.K. Jin, Y. Huang. Life prediction of composites using MMF and ATM. Strength\& Life of Composites, $2^{\text {nd }}$ Ed., 7.1-7.15 (2011).

19. P.S. Chua, Polym. Compos., 8(5), 308 (1987).

20. S. Mallarino, J.F. Chailan, J.L. Vernet, Eur. Polym. J., 41(8), 1804 (2005).

21. P. Georgiopoulos, E. Kontou, A. Christopoulos, Compos. B. Eng., 80, 134 (2015).

22. H.S.P. Silva, H.L. Ornaghi Jr., J.H.S. Almeida Jr., A.J. Zattera, S.C. Amico, Polym. Compos., 35(6), 1078 (2014). 
23. L.V. Silva, J.H.S. Almeida Jr., C.C. Angrizani, S.C. Amico, J. Reinf. Plast. Compos., 32(3), 197 (2013).

24. B.K. Daniels, N.K. Harakas, R.C. Jackson, Fibre. Sci. Technol., 3(3), 187 (1971).

25. C. Pigatto, J.H.S. Almeida Jr., H.L. Ornaghi Jr., A.L. Rodríguez, C.M. Mählmann, S.C. Amico, Polym. Compos., 33(12), 2262 (2012).

26. M. Akay, Compos. Sci. Technol., 47(4), 419 (1993).

27. Q. Qin and B. McKenna, J. Non-Cryst. Solids., 352(28-29), 2977 (2006).

28. N.T. Qazvini and N. Mohammadi, Polymer, 46(21), 9088 (2005). 